The use of patients in health care education the need for ethical justification

\author{
Linda Bindless University of Huddersfield, Yorkshire
}

\begin{abstract}
This paper addresses ethical concerns emanating from the practice of using patients for health care education. It shows how some of the ways that patients are used in educational strategies to bridge theory-practice gaps can cause harm to patients and patient-practitioner relationships, thus failing to meet acceptable standards of professional practice. This will continue unless there is increased awareness of the need for protection of human rights in teaching situations. Unnecessary exposure of patients, failing to obtain explicit consent, causing harm to vulnerable or disadvantaged groups and inappropriate use of information, though normally regarded as unacceptable professional practices, may go unrecognised in meeting educational needs, widening rather than narrowing theory-practice gaps.
\end{abstract}

(Fournal of Medical Ethics 1998;24:314-319)

Keywords: Health care education; theory-practice gap; professional accountability; human rights; codes of professional conduct

\section{Introduction}

Clearly the use of patients for health care education has always been a necessity and will remain so, both for the benefit of patient care and for students. Nevertheless there are important reasons for examining the ethical implications. Recent changes in health care education have led to increased demands for clinical placements and for greater involvement of patients in order to meet the requirements of new teaching and learning strategies, introduced to bridge theorypractice gaps. ${ }^{1}$ Use of some of these strategies has already attracted attention in academic journals ${ }^{2}$ and the popular press, ${ }^{3}$ where fears for the safety of patients and damage to patient-practitioner relationships have been expressed. Furthermore these concerns indicate that unless ways in which patients are used demonstrate expected standards of professional care to students, not only may patient care be jeopardised, but the extent to which educational objectives are met may also be limited, widening rather than narrowing theorypractice gaps. This paper provides an opportunity to increase awareness of situations where use of patients to meet new educational demands might be harmful to patients and students and go consider responses which appropriately dem strate protection of human rights and acceptaBle standards of professional health care practice.

\section{Standards of professional practice}

For most health care professionals employed within the National Health Service (NHS) in the United Kingdom (UK), standards of professiogal conduct and ethics are governed by statut\&ry regulation. For example, for doctors the regutatory body is the General Medical Coßnoil $(\mathrm{GMC})^{4}$; for nurses, midwives and health vistors it is the United Kingdom Central Couno Nursing, Midwifery and Health Visiti (UKCC) ${ }^{5}$; for chiropody, dietetics, medical latobratory sciences, occupational therapy, orthopt physiotherapy and radiography it is the Council for Professions Supplementary to Medicine (CPSM). ${ }^{6}$

Codes of ethics or of professional conduct,,$\frac{7}{50 f}$ necessity, address principles rather than particutar situations, such as teaching. The principles Tof medical ethics set out by the $\mathrm{GMC}^{7}$ are specifically designed to justify patients putting trust in their doctors, demanding that doctors must make the care of patients their first concesn. Ways of doing this include: showing consideration; respecting privacy and dignity; giving information; respecting the rights of patients to $\mathrm{e}$ fully involved in decisions about their care; beffig honest and trustworthy; and respecting/protectlig confidential information.

Likewise the $\mathrm{UKCC}^{8}$ makes plain that sadeguarding and promoting the interests of individual patients and clients is the first requirement professional accountability. Guidelines for prâctice of PSMs are produced by the individupal professional bodies which make up this group practitioners. A recent review of UK legislation governing the practice of this group of health core professionals ${ }^{9}$ gives a timely warning of the need to recognise changing attitudes in society towards professionals which renders them more account- 
able and of patients' expectations to have their rights respected.

Patients' rights and standards, as set out in the patient's charter ${ }^{10}$ suggest that in relation to teaching, patients have a right to: choose whether or not they want to take part in teaching, though it only mentions "medical student training"; clear explanations about proposed treatment, risks and alternatives before deciding whether to agree to it; know that NHS employees have a legal duty to keep records confidential; have complaints investigated, but can only "expect" respect for privacy and dignity and that staff will be easily identifiable.

Human rights law, however, provides a much clearer picture of what is required of professionals to protect human rights. ${ }^{11}$ In particular the Report to the Convention on Human Rights and Biomedicine $^{12}$ makes clear that professional standards cover all "interventions", which must be performed "in accordance with the law in general, as supplemented and developed by professional rules".

It seems quite clear that respect for patients ought to be the prime objective, not health care education. Even so, it appears that not all registered practitioners are aware of the need to uphold standards of professional practice and to protect patients' rights. Media reports ${ }^{3}$ of doctors and others facing disciplinary action because they have made inappropriate use of patients in teaching situations suggest that there is no room for complacency. Part of the problem may be failure to recognise the need for patient choice in teaching situations, or it could be that practitioners feel obliged to accommodate students. Or perhaps, here too, there is a theory-practice gap, in which practitioners know what is required of them, but because there has been no opportunity to consider how new approaches to education might be harming patients, do not take the necessary steps to avoid pitfalls. Examples which follow illustrate some of these situations. The first addresses unnecessary exposure of patients to students; the second illustrates the need-to make sure that patients freely consent; the third considers potential harms to vulnerable or disadvantaged groups, and the last examines strategies which call for information about patients.

\section{Rights to privacy and dignity: avoiding unnecessary or frequent exposure of patients} Most practising doctors, nurses, midwives and other health care professionals now receive frequent requests to provide clinical placements for students. In the past they were normally students at different stages of preparation for professional registration or qualified health care practitioners undertaking post-registration or continuing professional education, but nowadays it is not unusual to receive requests from undergraduates on non-vocational degree courses or students from colleges/schools wishing to gain workplace experience or vocational guidance.

In deciding how to respond to such requests, the need to show respect for privacy and dignity suggests that there are two important considerations: (1) the number of students that can be accommodated at any one time without jeopardising patient care (2) the learning needs of students, especially of "pre-vocational" or even "nonvocational" students seeking work experience.

Given the variety of students now requiring clinical placements to top up the theoretical component of their courses, it is becoming increasingly difficult for any one person to know how many students might be seeking access to the same patient/group of patients at the same time, even if an audit of the learning environment has been carried out by the educational provider. For some patients this may mean repeated exposure to students, few interactions with their professional carers going unobserved. Though a difficult task, there is obviously a need for practitioners to monitor the number of students seeking placements, and if necessary impose limits.

Accommodating pre-vocational or nonvocational students, while maintaining accountability for patient care, requires even more careful thought, especially if what patients are told about the identity of such students is less than honest. It is not unusual for students from universities or sixth-form colleges, some even younger, to seek placements in health care settings, either because they are studying health-related courses or are thinking about a career in one of the health professions. The learning needs of such students clearly differ from those of other students and may not justify the use of individual patients whereas for vocational students, patients might be essential. Both the frequent and the unnecessary exposure of patients have implications for morally acceptable practice which those making requests for placements might not recognise, or could not be expected to recognise unless told otherwise.

2. Rights to be involved in decisions about care: enhancing patient choice

Ensuring that patients understand what is going to happen to them and obtaining consent, either implied or explicit, are amongst the first lessons that many health care students are taught in the educational setting, as a way of avoiding civil actions for trespass to the person or negligence, or 
worse, a prosecution for assault. ${ }^{13}$ More importantly, it is necessary to show respect for patients..$^{7-8}$ An educational strategy implemented to narrow the theory-practice gap must start with sufficient evidence of patients freely consenting. A casual "You don't mind if a student watches" is clearly not enough; neither is asking permission with a student in tow. An obvious solution is to make sure that patients are always invited to "opt in" instead of being required to "opt out", especially as this is still accepted as the norm in all other areas of health care practice. ${ }^{14}$

But even this might not be enough to enable us to say that patients freely consent to being used for educational purposes. Legislation and codes of professional conduct may not be explicit, but there is an extensive literature about consent which suggests that merely asking permission may not be enough, from an ethical ${ }^{15}$ or a legal standpoint, ${ }^{16}$ to say that consent obtained in this way shows as much respect for patient autonomy as it might. This means considering whether patients' decisions to be used for teaching are likely to be influenced by other important factors. Harris $^{17}$ provides what would appear to be a particularly fitting framework for the identification of some of these. He reminds us that people's choices can be undermined or impaired by four different kinds of influences: control, reasoning, information and stability. Where evidence suggests that there may be "defects" in any of these areas, for example, exogenous controlling influences, faulty reasoning, misunderstandings or changed circumstances, then there may be good reason to suppose that consent has not been given as freely as it might have been. In teaching situations all of these could be important considerations.

\section{A) CONTROL}

Three types of controlling influences are usually recognised in ethical discourse. These are persuasion, manipulation and coercion. ${ }^{18}$ Using Beauchamp and Childress's definitions, ${ }^{18}$ persuasion, the weakest form of control, relies on the merit of the reasons offered, whereas manipulation and coercion are stronger controlling influences. Manipulation commonly uses deception to falsify facts and coercion uses credible and severe threats of harm. Of the three, it is generally accepted that persuasion is the most easily justifiable form of control and may even be welcomed by some patients, but that the other two may only exceptionally be justifiable. It is difficult to see how a teaching situation could warrant such strong control. Yet in health care settings a perceived, albeit not intentional, unequal power relationship between health professionals and their patients may convince some patients that they ought to take part in stude्क्रुt teaching. The task is therefore to distinguish between approaches to patients which persua्, involvement, from those which could constitute unjustifiable abuse of control, and to some extenta threat to human rights.

\section{B) REASONING}

If reasoning is flawed there is a chance that consênt might not have been freely given, but it does rot necessarily follow. ${ }^{19}$ It seems quite likely that substantial numbers of patients might agree to involved in health care education, because they believe that health professionals only act in the biest interests of their patients and would not therefor ask them to do anything which might not be góid for them. The decision to do so is based on trust, which forms the basis of the therapeutic relationship on which the current system of self-referral relies. This in itself does not amount to flawed raasoning, so long as professionals really do only \&্k patients to do things that they think will be in the best interests of patients. It is therefore alw $\overrightarrow{\text { sys }}$ important that practitioners satisfy themselve 8 thet patients used in education will not come to Failure to do this would not only mean that con̄isent had not been freely given, but any abuse of trifst perceived by patients could lead to long term dranage to the patient-practitioner relationship.

\section{C) INFORMATION}

Beliefs or choices based on false or incomplete information are bound to be flawed to some extent. ${ }^{20}$ It should therefore go without saying patients who agree to be used in teaching oughtoto be fully informed about the nature of the studeris' status and the anticipated extent of student involvement in their care. Misunderstandiogs which can arise from use of the term "studegt" may be accidental or deliberate. Post-registration students, such as qualified doctors or nurses parsuing additional "specialist" courses of study, Rुut introduced as "students" may cause patiepts undue worry, unless the position is made clear. $8 \mathrm{~g}$ the other hand, the temptation to avoid explatesations for the presence of non-vocational gor pre-vocational students in attempts to increase acceptability are obviously to be deplored. Si ̌milarly, inappropriate use of uniforms or white cơts condones deception of patients. Whether or झłot patients ought to be used in such situations is prhaps only something which patients can ßay. However, the extent to which decisions of pationts can be said to be informed is only somethe which can be ascertained by those who know what the patients were told. Being honest ${ }^{7-8}$ about the 
extent of student involvement is just as important. In practice few informed patients are likely to object to observation by students or to supervised practice, but may be less happy about students taking responsibility for care over a prolonged period, or about being directly involved in formal assessment of the students' practice. This may lead to feelings of insecurity or desertion, particularly in community settings when students visit alone, or even guilt on the part of patients if students fail assessments.

\section{D) STABILITY}

Over periods of time it is not unusual for people to change their minds about decisions made, either because they had not appreciated the full implications of their decisions, because of unpleasant consequences, or because of changed circumstances. Given that there may be rare occasions when nothing can be done to alter those decisions, in the main, decisions made and later regretted are redressed, either by not proceeding, or by withdrawing at the first opportunity and not repeating the experience. Patients, like all other people, can be expected to change their minds. Until patients have experienced exposure to students they have no way of knowing how it will feel to be subjected to learners or what difference the presence of students may make to care received. Furthermore, during periods of illness, especially at the stage of investigation, it is often not possible for either patients or their professional carers to anticipate questions or examinations required, some of which may be intimate. But unlike others, patients often perceive it as being more difficult for them to change their minds. In teaching situations this may be due to the inability of some students to recognise signs and symptoms of patients' regretted decisions, or to the thoughtlessness of their supervisors. One solution is to adopt a system of "process consent", rather than a once-and-for-all consent. ${ }^{21}$ This system is advocated for use in qualitative research, where unscripted interviewing schedules often lead to unexpected questioning or where observations become intrusive. It gives participants the opportunity to renegotiate the terms of consent on a regular basis. As the need for care may be equally unpredictable, adoption of process consent would make it easier for patients to opt out.

Educational strategies such as contract learning and continuous assessment may also inhibit patients' choices. Many students commence placements with a set of learning outcomes to be achieved by the end of a specified period. At best, these are negotiated with their placement facilitators and with patients as part of a "learning contract"26; at worst learning outcomes are pre-determined by educational providers, who have no direct responsibility for patient care. The need for students to meet learning outcomes can put considerable pressure on facilitators to maximise teaching opportunities, rather than consider patient choice.

Continuous assessment can be another problem associated with workplace learning. Instead of one final assessment, there may be formative or summative periodic assessments, with or without final assessment. ${ }^{23}$ All too often, the demonstration of developing skills requires students to apply theory to practice with reference to the continuing care of one particular patient. When completion of assessments for costly educational courses (increasingly at the students' own expense, especially to meet continuing education requirements) are at stake, it is not difficult to imagine the pressure which might be brought to bear on reluctantly participating patients. The threats to patient choice posed by these educational influences may not be widely recognised, but deserve consideration. For instead of reducing the theorypractice gap, at least as far as patient choice is concerned, failures by practitioners to acknowledge that patients might want to change their minds only widens the gap.

\section{Rights to choose whether or not to take part in medical research or medical training: protecting patients accessed for particular or unique conditions}

Students' learning needs sometimes require access to particular groups of patients to meet the requirements of courses. These may include patients with sexually transmitted diseases, incontinence or life-threatening disease, all commonly associated with physiological, social and psychological distress, which may make them more vulnerable to harm than some other patients. Harms include over-exposure, invasions of privacy, and questionable motivation for agreeing to take part, either to gain anticipated privilege, from misplaced altruism, or because of the controlling influence of their carers. In particular, concerns have been expressed ${ }^{24}$ about "captive" groups, such as pregnant women, prisoners and patients in residential homes. It has already been suggested that such patients should not take part in research without having given express, specific consent (rather than merely implied) ${ }^{25}$; doing likewise for use in teaching could afford some protection. Similar concerns apply to those unable to give their own consent due to age, infirmity, mental illness, or other temporary or permanent incompetence. For the protection of patients unable to 
consent, adoption of the Convention on Human Rights and Biomedicine would establish the principle of protection that intervention must only be for the direct benefit of the person. ${ }^{26}$

The use of patients with rare conditions requires further considerations: (1)Establishment of the extent of the educational benefit. Should patients come to realise that exposure was nothing more than morbid curiosity, the harm to the patient-practitioner relationship might be out of all proportion to the educational gain. (2)It may be necessary to decide which students are likely to gain most benefit, so avoiding over-exposure of the patient. It seems unlikely that non-vocational or pre-vocational students would gain any extra benefit from the experience, whereas the opportunity could be very important for qualified practitioners undertaking post-registration or continuous professional education. (3)The implications of creating a false sense of importance. It is not unusual for patients to feel let down or rejected by their regular carers when students leave their placements, especially if they have been the centre of attention. Although this may happen to any patient involved in teaching, those with rare conditions are more likely to be targeted for attention on more than one occasion, as in the qualifying examinations of medical students.

\section{Right to confidentiality: respecting and protecting information about patients}

Educational strategies used to assess students' ability to apply theory to practice encourage use of information about patients. They include use of case studies, critiques of episodes of care, critical incidents, diaries, reflection "on" and "in" practice, videotaped recordings and photographs, and portfolios. The importance of gaining consent to avoid breaching confidentiality, though not always appreciated, ${ }^{27}$ should go without saying. However, it is doubtful whether many patients realise that intimate details might be shared with supervisors in clinical placements, other students and academics, in discussion or written assignments. Unless it is made clear that informed consent is a requirement and that patients' identities must be protected, encouraging students to use information about patients for reasons other than their direct care perpetuates rather than narrows theory-practice gaps.

\section{Demonstrating ethical practice}

Both the $\mathrm{GMC}^{7}$ and the UKCC ${ }^{8}$ stipulate that the first duty of their members is to their patients; the GMC points out that this is to justify patients putting trust in their doctors, while the UKCC directs that nurses, midwives and health visito should act, at all times, to safeguard and promote the interests of individual patients and cliens. Similarly, recommendations for the regulation $\neq f$ professional conduct of other health care practitioners, such as the PSM, ${ }^{9}$ acknowledge the changing culture of health care and the need awareness of patients' rights and fundamen Fal freedoms. Use of educational strategies, designed to bridge theory-practice gaps, which require the involvement of patients can only be effective $\vec{a} f$ registered practitioners are seen to show respect for patients. But even if most practitioners are ordy too aware of this need, pressures to accet requests for placements, misunderstandings aboßht the learning needs of different types of students, failure to protect vulnerable groups, and use $\mathrm{CO}_{\mathrm{G}} \mathrm{f}$ unfamiliar educational assessment strategies maty lead to demonstration of practice which does not put patient care before students' needs.

Examples, set out above, provide an opp@tunity to consider some of the pitfalls, and to coltemplate ways in which the use of patients can justified by showing that their needs come first, narrowing rather than widening theory-prastioe gaps.

Linda Bindless, $M A, B A$, Cert Ed, DN Cert, RGA Senior Lecturer, School of Human and Heagish Sciences, The University of Huddersfield, Queensgatio, Huddersfield, Yorkshire.

\section{References}

1 Hewison A, Wildman S. The theory-practice gap in nursing. a new dimension. Fournal of Advanced Nursing 1996:24:754-6.

2 Grimley Evans J. Ethical problems of futile research. Fournä of Medical Ethics 1997:23:5-6.

3 Milhill C. Schoolboy assisted in operation. The Guardian 1997 Aug 2: 2.

4 Medical Act, 1983.

5 Nurses, Midwives and Health Visitors Act, 1979.

6 Professions Supplementary to Medicine Act, 1960. 7 General Medical Council. Good medical practice. Londegn:

8 United Kingdom Central Council of Nursing, Midwifery and Health Visiting. Code of professional conduct [3rd ed]. Londen:
UKCC, 1992.

9 JM Consulting Ltd. The regulation of health professions: reportof a review of the Professions Supplementary to Medicine Act (1980) with recommendations for new legislation Bristol: JM Consulking Ltd, 1996.

10 Department of Health. The patient's charter and you. Lond\& HMSO, 1996.

11 Montgomery J. Health care law. Oxford: Oxford University Press, 1997: 18-19.

12 Council of Europe. Explanatory report: convention on hu rights and biomedicine. Strasbourg: DIR/JUR (97) 1, 1997: 990.

13 Brazier M. Medicine, patients and the law [2nd ed]. London: Penguin, 1992: 73-5.

14 British Medical Association. Medical ethics today. Longुn: BMJ, 1993: 19.

15 Harris J. The value of life. London: Routledge, 1985: 200.

16 See reference 13: $\operatorname{ch} 4$.

17 See reference 15: 196-200.

18 Beauchamp TL, Childress JF. Principles of biomedical ethics 0 ed]. New York: Oxford University Press, 1989: 107-11.

19 See reference 15: 197-8.

20 See reference 15: 198. 
21 Raudonis BM. Ethical considerations in qualitative research with hospice patients. Qualitative Health Research 1992:2:23849.

22 Mazhindu GN. Contract learning reconsidered: a critical examination of implications for application in nurse education. fournal of Advanced Nursing 1990:15:101-9.

23 Rowntree D. Assessing students: how shall we know them? London: Kogan Page, 1987.
24 For example: Fulford KWM, Howse K. Ethics of research with psychiatric patients: principles, problems and the primary responsibilities of researchers. Fournal of Medical Ethics 1993:19:85-91.

25 See reference 12: article 5.37

26 See reference 12: article 6 .

27 Smith R. Commentary: the importance of patients' consent for publication. British Medical fournal 1996:313:16.

\title{
Further comments on Omentum-to-Brain Transplants
}

\author{
FROM THE JOURNAL'S ASSESSOR, DR SAMUEL SMITH, GENERAL PRACTITIONER
}

I like this poem, and I like it more having spent some time unravelling the rather obscure neurological and neuropathological allusions. The cingulate gyrus is part of the limbic system involved in emotion and memory; the Alzheimer twos refer to neurofibrillary tangles found in the histopathology of Alzheimer's disease; the thirsty bouton belt, I presume, refers to regions rich in synaptic connections; and Wernicke's encephalopathy most of us can remember something about. The simplistic jokes might be directed at the hapless demented, or perhaps be provoked by the bizarre impulse to transplant gut to brain. But beyond them lies a response to a cruel incapacity; one which might be ameliorated by the bouncing blood, driving back the shadows, although not completely resolving the alimentary confusion of keys and peas. I did not find anything on Lendrum's stain, which may not be important anyway presumably a neurohistological stain - but the reference to Eleanor Roosevelt also remains a puzzle. It could just be that she continued to be politically active long after her husband's death, rather than slip into dementia. I don't know. Anyway, I do recommend the poem be published as it is; something to make one think, captured between title and reference in a learned journal. The allusions, once unravelled, add resonance to the pleasing aesthetic structure.

FROM THE POET

I thank you and your assessors for approving my poem, Omentum to Brain Transplants. I am pleased to comment about several obscure references, while mindful that simplifications will satisfy some readers - especially non-medical scholars, but may dampen fanciful comparisons that attract others.

Concordance-wise:

- Mrs Roosevelt did not have Alzheimer's disease, but she did own a last syllable that rhymes with bouton belt.

- I introduced the eponym Wernicke's because some readers like occasional rhymes, and I had assumed that most readers would conclude that Wernickes caused the problem with car keys.

- One of your reviewers suggested that the fresh blood flowing up from the omentum may be harmful in ways not understood. This is certainly true and will surely be part of the ongoing scientific evaluations.

- I am, however, proud of the many gastro-physiologic phenomena I refrained from mentioning, for example, eructations and flatulance. Should I write a sequel describing what Jalapeno peppers caught in the lesser curvature, might do to blood flow aimed at the temporal lobe or a more romantic gyrus?

* You understand that this has been a speculative poetic effort in no way critical of Dr Goldsmith, whose imagination and perseverance may lead to astoundingly successful new therapies. 